\title{
How does renewable energy consumption affect economic growth? Evidence from the European Union countries
}

\author{
Natalia Davidson ${ }^{1 *}$,Elizaveta Maksimova ${ }^{1}$, and Oleg Mariev ${ }^{1}$ \\ ${ }^{1}$ Ural Federal University, Graduate School of Economics and Management, Mira Street 19, \\ Ekaterinburg, Russia
}

\begin{abstract}
Research background: Fossil fuels are used at such a high rate that they are currently being depleted. Moreover, they are associated with a greenhouse effect leading to global warming. Meanwhile, green energy is naturally replenished and fosters sustainable development (Nelson and Starcher, 2015). However, the empirical evidence of the impact of green energy on economic growth is controversial (Adewuyi and Awodumi, 2017; Chen et al., 2020; Destek and Aslan, 2017; Zafar et al., 2018).

Purpose of the article: This paper analyses the impact of renewable energy consumption on economic growth in the European Union (EU) countries. This is important in line with the goals of EU to shift towards green energy during the coming years (Directive (EU) 2018/2001).

Methods: We use data of the World Bank and Our World in Data over 1990 to 2015 for $28 \mathrm{EU}$ countries. We estimate the impact of renewable energy consumption on the countries' gross domestic product. The control variables are labor force, research and development, and foreign direct investment. We apply the pooled mean group, mean group, the dynamic fixed effect estimators (Pesaran, 1997; Pesaran et al., 1999), and generalized method of moments (Arellano \& Bond, 1991).

Findings \& Value added: Results show that the renewable energy consumption positively affects economic growth of the EU countries. We contribute by shedding light on the possibility to develop renewable energy, while achieving economic growth. The results have important implications for economic policy.
\end{abstract}

Keywords: renewable energy; economic growth; sustainable development; European Union countries.

JEL Classification: $Q 20 ; Q 42 ; O 44$

${ }^{*}$ Corresponding author: natalya.davidson@gmail.com 


\section{Introduction}

Fossil fuels are used at such a high rate that they are currently being depleted. Moreover, they are associated with a greenhouse effect leading to global warming. Meanwhile, green energy is naturally replenished and fosters sustainable development (Nelson and Starcher, 2015). However, the empirical evidence of the impact of green energy on economic growth is controversial (Adewuyi and Awodumi, 2017; Chen et al., 2020; Destek and Aslan, 2017; Zafar et al., 2018).

According to the environmental Kuznets curve hypothesis, economic growth increases environmental pollution up to a certain point of income, and then environmental pollution starts decreasing (Grossman \& Krueger, 1995). This decrease becomes possible both due to better technologies, and higher environmental standards. In this process demand from population and economic policy measures are important (Davidson et al., 2021). However, the other side of this process is also of practical interest: how do economic policy measures, aimed at reducing environmental pollution, affect economic growth?

One of the directions of economic policy is promoting renewable energy to reduce harmful consequences associated with utilization of fossil fuel. This paper analyses the impact of renewable energy consumption on economic growth in the European Union (EU) countries. This is important in line with the goals of EU to shift towards green energy during the coming years (Directive (EU) 2018/2001).

It can be assumed that the European Union countries that are on the advanced stage of development are relatively more concerned with the environmental issues and, therefore, with development of renewable energy. At the same time, it is of interest to find the actual impact of renewable energy on economic growth of the countries.

We use data of the World Bank and Our World in Data over 1990 to 2015 for 28 EU countries. We estimate the impact of renewable energy consumption on the countries' gross domestic product (GDP). The control variables are labor force, research and development, and foreign direct investment.

We apply the pooled mean group (PMG), mean group (MG), the dynamic fixed effect (DFE) estimators, and generalized method of moments (GMM). GMM accounts for endogeneity (Arellano \& Bond, 1991); MG, PMG and DFE estimators account for endogeneity and provide short- and long-run estimates (Pesaran, 1997; Pesaran et al., 1999).

Results show that the renewable energy consumption positively affects economic growth of the EU countries. We contribute by shedding light on the possibility to develop renewable energy, while achieving economic growth. The results have important implications for economic policy.

\section{Literature review}

At present in the world there are 'dirty' and 'clean' sources of energy. 'Dirty' sources are fossil fuels: coal, oil and gas, that are associated with environmental pollution and are being depleted. Unlike these sources, 'clean energy' comes from natural renewable sources and has a smaller negative impact on the environment. It includes energy of sun, wind, moving water (hydropower, wave and tidal energy), heat below the earth surface (geothermal energy), biomass (such as wood, waste, and crops) (Nelson and Starcher, 2015).

Among the advantages of renewable energy sources are decrease in $\mathrm{CO}_{2}$ emissions, contribution to environmental protection, relying on the internal energy sources, and increase in employment opportunities in the new sector of the economy. Renewable energy is closely associated with the Sustainable development goals introduced by the United Nations at the Earth Summit in Rio de Janeiro, Brazil, in 1992 that imply balance between economic development, social progress and environmental protection (United Nations, 2015). In 2015 The Sustainable Development Goals (SDG) 2030 Agenda containing 17 sustainable 
development goals was signed and accepted by all UN member nations (United Nations, 2015).

In the European Union the Directive on the promotion of the use of energy from renewable sources was signed in 2009, implying the use of $20 \%$ of energy from the renewable sources in all countries by 2020 ; this goal varies from $10 \%$ to $49 \%$ in different countries. According to the new Directive signed in 2018, European Union member countries should decrease greenhouse gas emissions by no less than $40 \%$ by year 2030 compared to 1990 , increase the share of renewable energy sources up to $32 \%$ and increase energy efficiency by no less than $32.5 \%$ (European Union, 2018).

In 2018 the share of renewable energy in the final energy consumption was $18 \%$, and in 2019 it became $18.9 \%$. Sweden was the leader in renewable energy in 2018 , with $54.6 \%$ of energy coming from the renewable sources, followed by Finland with 41.2\%, Latvia with 40.3\%, Denmark with 36.1\% and Austria with 33.4\% (European Union, 2020).

To address the impact of energy consumption on economic growth, economic growth models are useful. Such models were proposed by Roy Harrod and Evsey Domar, and developed by Robert Solow, Robert Barro and Paul Romer.

Current results on the impact of renewable energy consumption on economic growth are controversial: this impact is found to be positive, negative, or neutral (Adewuyi \& Awodumi, 2017). Muhammad et al. (2017) analyzed 29 countries using data from 1990 to 2014 and found positive and significant impact of renewable energy consumption on economic growth, confirming this causal relation with Granger causality test. Soava et al. (2018) also found positive impact of renewable energy consumption on economic growth, based on data for 28 European Union countries for years 1995-2015; in this case Granger causality test showed either unidirectional or bidirectional relations between renewable energy consumption and economic growth for different countries.

Chen et al. (2020) found that the impact of renewable energy consumption on economic growth is positive and significant only when developing countries and countries - not OECD members overcome a certain threshold of renewable energy consumption; otherwise, this impact is negative. They also found no significant impact for developed countries and positive and significant impact for OECD countries. Inglesi-Lotz (2016) found that the increase in renewable energy consumption increases GDP and GDP per capita in the OECD countries based on data for 1990-2010.

Employing US data for 1965-2016 and ARDL model, Gozgor (2018) found that both economic complexity and renewable energy consumption increase economic growth. Gozgor et al. (2018) used ARDL and panel quantile regression methods to study 29 OECD countries in 1990-2013 and concluded that both economic complexity and consumption of energy from non-renewable and renewable sources are associated with increase in economic growth. Rafindadi and Ozturk (2017) revealed bidirectional relations between renewable energy consumption and economic growth in Germany based on quarterly data from 1971 to 2013 and several methods including ARDL and Granger causality test.

Let us turn to the studies which found neutral or negative impact of renewable energy consumption on economic growth, at least for some countries or energy sources. Alper and Oguz (2016) studied the causal relations between economic growth, renewable energy consumption, capital and labor in the new member states of the EU in 1990-2009 using ARDL and found significant positive impact only for Bulgaria, Estonia, Poland, and Slovenia. Based on data for 20 OECD countries covering years 1990-2008, Ohler and Fetters (2014) found that biomass, hydroelectric power, waste and wind are positively related with GDP in the long run. They also found short-term bidirectional causal relation only between hydroelectric power and waste on one hand and GDP growth on the other hand.

Destek and Aslan (2017) studied the impact of renewable and non-renewable energy sources on economic growth in 1980-2012 for 17 developing countries based on panel data and found a unidirectional positive impact of renewable energy on economic growth for Peru (growth hypothesis was confirmed), while the conservation hypothesis was confirmed for 
Colombia and Thailand (unidirectional link from economic growth to renewable energy), the feedback hypothesis holds for Greece and South Korea (there is bidirectional causality), and for 12 developing countries the relation turned out to be neutral. Overall, the findings imply that renewable energy causes economic growth in Peru, Greece, and South Korea.

Empirical research also deals with the impact of renewable energy sources on economic growth and $\mathrm{CO}_{2}$ emissions. Banday and Aneja (2020) studied this issue for BRICS countries based on data for 1990-2017. They found unidirectional link from GDP to $\mathrm{CO}_{2}$ for India, China, Brazil, and South Africa, but no causal relations for Russia. As for the causal link between renewable energy consumption and GDP, they confirmed feedback hypothesis for China and Brazil, growth hypothesis for Russia, conservation hypothesis for South Africa and neutrality for India. Belaid and Zrelli (2019) studied nine Mediterranean countries based on data for 1980-2014 using ARDL method. They found empirical evidence of short-term bidirectional link between GDP, renewable energy consumption and $\mathrm{CO}_{2}$ emissions. Ito (2017) based on panel data covering 42 developing countries for the period 2002-2011 found that non-renewable energy consumption negatively affects their economic growth, while renewable energy consumption has a positive long run effect on economic growth.

Overall, there is empirical evidence supporting the idea that while transferring towards 'green economy' countries can sustain and promote economic growth. At the same time, the findings vary in the current literature, and the question concerning the relation between renewable energy and economic growth remains open. The next section is devoted to data and methods that we use to study this issue.

\section{Data and methodology}

We use panel data over the period 1990-2015 for 28 EU countries from the databases of the World Bank and Our World in Data. The data covers the following countries: Austria, Belgium, Bulgaria, Hungary, Germany, Greece, Denmark, Ireland, Spain, Italy, Cyprus, Latvia, Lithuania, Luxembourg, Malta, Netherlands, Poland, Portugal, Romania, Slovakia, Slovenia, Finland, France, Croatia, Czech Republic, Sweden, Estonia, and the UK. The UK is included in the analysis as our data covers the period 1990 to 2015, and at that time the country belonged to the European Union.

We analyze the relation between economic growth, renewable energy consumption, labor force, expenditures on R\&D and foreign direct investment (FDI) in the EU countries. The World Bank data (World Development Indicators) provides us with the following indicators for the period 1990-2015: GDP (in current US dollars), renewable energy consumption (\% from the total final energy consumption), labor force (total), expenditures on R\&D ( $\%$ from GDP) and net FDI (in current US dollars). Our World in Data database provided us with energy consumption variables measured in terawatt hours (TWh).

As for GDP, in 1990 the leading countries were Germany, France, and Italy. In 2015 Germany, Great Britain, and France had the highest GDP. The countries whose GDP grew the most between 1990 and 2015 are Poland, Slovakia, Ireland, and Czech Republic.

Let us compare the use of renewable energy in the countries of the European Union from 1990 and 2015. In 1990 the countries with the highest levels of renewable energy use were France, Austria, Germany, Spain, Finland, and Sweden. Malta had the lowest level of the renewable energy consumption among the EU countries; Cyprus occupied the twentyseventh place. Malta and Cyprus increased their renewable energy consumption from 1990 to 2015. However, these countries' renewable energy consumption remains the lowest in the European Union.

In 2015 Germany had the highest level, France was the next, followed by Sweden. Czech Republic, Belgium and Denmark had approximately the same level of renewable energy consumption, slightly lower than the countries mentioned before. 
Table 1 below presents descriptive statistics of variables that we use to find out the impact of renewable energy consumption on economic growth.

Table 1. Descriptive statistics.

\begin{tabular}{|c|c|c|c|c|c|}
\hline Variable & Obs & Mean & Std. Dev. & Min & Max \\
\hline $\ln$ GDP & 728 & 25.520 & 1.779 & 21.658 & 28.988 \\
\hline $\ln R E C$ & 728 & 23.874 & 2.024 & 13.561 & 26.994 \\
\hline $\ln L F$ & 728 & 15.112 & 1.410 & 11.823 & 17.567 \\
\hline $\ln R D$ & 728 & 20.991 & 2.383 & 13.880 & 25.436 \\
\hline $\ln$ FDI & 728 & 22.002 & 2.119 & 14.509 & 27.322 \\
\hline
\end{tabular}

Table 1 shows that we have a balanced panel, as observations for all variables in the dataset are present for all 28 countries for 26 years. Standard deviation shows that the dispersion of the variables relative to the mean is not very large.

To find the effect of renewable energy consumption on economic growth, we are estimating the following model:

$$
\ln G D P_{i t}=\beta_{0}+\beta_{1} \ln R E C_{i t}+\beta_{1} \ln L F_{i t}+\beta_{1} \ln R D_{i t}+\beta_{1} \ln F D I_{i t}+\mu
$$

where GDP is gross domestic product; REC is renewable energy consumption, LF is labor force, $\mathrm{RD}$ is expenditures for research and development, and FDI is foreign direct investment. All variables are in logarithms; $\mu$ is error term, $i$ reflects countries, and $t$ reflects years.

To estimate models based on panel data, Fixed Effects Method and Random Effects Method can be used. However, they do not fully account for the differences between countries: the intercepts differ across groups, but other coefficients and error variances are assumed to be the same (Pesaran et al., 1999). Autoregressive distributed lag (ARDL) model is an appropriate method in case of such differences. This method includes Mean Group (MG) estimator, Pooled Mean Group (PMG) estimator and Dynamic Fixed Effect (DFE) estimator introduced by Pesaran (1997) and Pesaran et al. (1999). ARDL method allows to receive short- and long-term estimation.

In our data both the number of time periods, $\mathrm{T}$, and the number of groups, $\mathrm{N}$, are large, and the order of magnitude is the same, therefore, these methods are suitable. MG estimates $\mathrm{N}$ regressions and calculates the coefficient means. MG estimator, the mean of the estimates, produces consistent estimates of the average of the parameters (Pesaran et al., 1999). However, MG does not consider that certain parameters can be the same across groups.

In its turn, PMG treats the long run coefficients as identical, while the intercepts, the short run coefficients and error variances are different across groups. The economic intuition behind this is that some factors, such as common technologies can influence all groups (in our case, countries) similarly in the long run, while in the short run their impact can be different across groups.

DFE constrains all the slope coefficients and error variances to be the same. The DFE standard errors can be corrected for the heteroskedasticity of error variances across groups. An advantage that PMG has over a more traditional DFE model is that the short-run dynamic specification can differ across countries.

Generalized method of moments (GMM) accounts for endogeneity problem arising both from unobserved heterogeneity between countries and from simultaneity, although it does not distinguish between short and long run effects (Arellano \& Bond, 1991; Pesaran et al., 1999). 
In the literature the following hypotheses relating energy consumption and economic growth are considered. We rely on these hypotheses to analyze a possible causal link between renewable energy consumption and economic growth in the EU countries.

The first hypothesis suggested in the literature implies that energy consumption in general increases economic growth, and this causality is unidirectional. This approach implies a crucial role of energy consumption for economic growth and raises concern about reducing the energy consumption. The second hypothesis is the feedback hypothesis. It implies presence of bidirectional causal effect between energy consumption and economic growth. In this case, policy aimed at reducing energy consumption is also assumed to negatively affect economic growth, as energy consumption is both a principal determinant and a result of economic growth. However, we suppose that energy efficiency and green energy allow to protect environment without implying lower levels of economic growth.

The third hypothesis present in the literature is the conservation hypothesis, which claims a unidirectional causality with economic growth affecting energy consumption. If this hypothesis holds, then reducing energy consumption will not harm economic growth. The fourth hypothesis, the neutrality hypothesis, claims the absence of causal link between energy consumption and economic growth. In such situation, reducing energy consumption will not affect economic growth (Destek and Aslan, 2017).

Having analyzed the existing research and taking into account the advanced stage of economic development in the EU countries, we put forward the hypothesis that renewable energy consumption positively affects economic growth in this group of countries.

\section{Results}

Based on the mean group (MG) estimator, pooled mean group (PMG) estimator, dynamic fixed effect (DFE), and generalized method of moments (GMM) we received the following results (see Table 2 below). The variable renewable energy consumption (REC) is of our main interest, and the dependent variable is the logarithm of gross domestic product (GDP).

Table 2. Econometric estimation of economic growth determinants.

Dependent variable: $\operatorname{lnGDP}$

\begin{tabular}{|c|c|c|c|c|c|c|c|}
\hline & \multicolumn{2}{|c|}{ MG } & \multicolumn{2}{|c|}{ PMG } & \multicolumn{2}{|c|}{ DFE } & \multirow[t]{2}{*}{ GMM } \\
\hline & long run & short run & long run & short run & long run & short run & \\
\hline $\operatorname{lnREC}$ & $0.30 * *$ & $0.02 *$ & $-0.28 * * *$ & -0.0002 & $0.68^{*}$ & 0.04 & $0.14 * * *$ \\
\hline & $(0.12)$ & $(0.05)$ & $(0.09)$ & $(0.049)$ & $(0.40)$ & $(0.03)$ & $(0.02)$ \\
\hline $\operatorname{lnLF}$ & $1.61 *$ & $1.02 * * *$ & $9.93 * * *$ & 0.543 & 2.04 & 0.35 & $0.93 * * *$ \\
\hline & $(1.22)$ & $(0.38)$ & $(0.97)$ & (0.37) & (2.91) & $(0.29)$ & $(0.04)$ \\
\hline $\operatorname{lnRD}$ & $0.46^{* * *}$ & $0.62 * * *$ & -0.08 & $0.62 * * *$ & 0.47 & $0.41 * * *$ & $0.12 * * *$ \\
\hline & $(0.13)$ & $(0.07)$ & $(0.06)$ & $(0.07)$ & $(0.29)$ & $(0.03)$ & $(0.03)$ \\
\hline $\operatorname{lnFDI}$ & $0.04 *$ & $0.01 * *$ & $0.12 * * *$ & $0.01 * *$ & -0.05 & $0.01 * *$ & $0.28 * * *$ \\
\hline & $(0.02)$ & $(0.01)$ & $(0.03)$ & $(0.01)$ & $(0.15)$ & $(0.004)$ & $(0.04)$ \\
\hline Const. & & $13.16^{* * *}$ & & $6.77 * *$ & & 0.77 & $4.63 * * *$ \\
\hline & & $(4.97)$ & & (3.06) & & $(0.85)$ & $(0.59)$ \\
\hline Obs. & 728 & 728 & 728 & 728 & 728 & 728 & 727 \\
\hline
\end{tabular}

$* \mathrm{p}<0.05, * * \mathrm{p}<0.01, * * * \mathrm{p}<0.001 ;$ standard errors are in parentheses 
All short-run coefficients (except for REC in PMG model) are positive, while their significance varies. As all variables are in logarithmic form, we see the elasticities of economic growth with respect to each of the variable.

According to Hausman test MG model describes data in the most accurate way. Therefore, we can conclude that renewable energy consumption (REC) positively affects economic growth both in the short and long run. The choice of MG over PMG model can be explained by the fact that the relations between the considered variables differ across countries both in the short and in the long run, while in the PMG model the coefficient are constrained to be homogeneous for all countries.

For generalized method of moments (GMM), R-squared equal to $75.29 \%$ and Wald test (Wald chi2(4) = 3172.19) indicate that the model describes the data accurately.

\section{Discussion}

The results showed positive impact of renewable energy consumption on GDP both in the short and long run. This finding confirms our hypothesis that renewable energy consumption positively influences economic growth in the countries of European Union.

In MG model $1 \%$ change in renewable energy consumption (REC) will lead to $0.02 \%$ change in gross domestic product (GDP) in the short run and to $0.3 \%$ change in the long run. We rely on this result, as Hausman test shows that MG model describes data in the most accurate way. The results of GMM estimation confirm the findings of MG model on the significance and sign of renewable energy consumption (REC) variable. According to GMM estimation results, $1 \%$ change in REC will lead to $0.14 \%$ change in GDP. Although the results of the existing research are controversial, our findings are in line with several papers (InglesiLotz, 2016; Muhammad et al., 2017; Soava et al., 2018).

The other variables included in the model also proved to be positive and significant in MG and GMM models, indicating positive contribution of labor force (LF), expenditures for research and development (RD) and FDI to economic growth in the short and long run. For example, $1 \%$ growth of R\&D expenditures leads to $0.62 \%$ increase in GDP in the short run and to $0.46 \%$ increase in the long run in MD model, while GMM model shows $0.12 \%$ increase. In all models this variable is significant at $1 \%$ significance level. These results can be explained based on the economic growth models emphasizing the role of investment, human capital, and R\&D for economic growth (Romer, 1990).

The results imply that while renewable energy consumption helps the EU-28 to reduce environmental pollution, it also enhances economic growth. Therefore, renewable energy can help the countries to develop 'green economy', to reduce carbon emissions, and to achieve the Sustainable Development Goals (United Nations, 2015). This underscores the importance of new technologies and policy initiatives aimed at renewable energy. Our results also imply that it is worth considering development of renewable energy sources in the other countries as well.

\section{Conclusion}

One of the global challenges facing all countries of the world is finding a balance between reducing environmental impact and achieving sustainable economic growth. Such energy sources as natural gas, coal and oil remain popular today. These are non-renewable types of fuel, and their extraction leads to the devastation of natural resources.

Renewable energy sources such as solar energy, wind energy, geothermal energy and others can be an excellent alternative. Switching to these resources has several benefits. The most important of these are: reducing carbon dioxide emissions, protecting the environment, reducing dependence on foreign sources, and promoting employment. 
We investigated the relationship between renewable energy consumption and economic growth in the European Union countries and the UK based on panel data over the period 1990-2015. After considering a range of methods used in the literature, we applied MG, PMG, DFE and GMM methods. Our findings confirm that renewable energy consumption positively and significantly affects economic growth in the studied countries.

Based on our results, we conclude that the European Union countries will benefit from further transition to renewable energy. The results of our research can be useful for the further promotion of renewable energy sources, as well as for investment in this industry.

\section{Acknowledgements}

Research was supported by the grant of the Russian Science Foundation № 19-18-00262 "Empirical modelling of balanced technological and socioeconomic development in the Russian regions".

\section{References}

1. Adewuyi, A. O., \& Awodumi, O. B. (2017). Renewable and non-renewable energygrowth-emissions linkages: Review of emerging trends with policy implications. Renewable and Sustainable Energy Reviews, 69, 275-291.

2. Arellano, M., \& Bond, S. (1991). Some tests of specification for panel data: Monte Carlo evidence and an application to employment equations. Review of Economic Studies, 58(2), 277-297.

3. Alper, A., \& Oguz, O. (2016). The role of renewable energy consumption in economic growth: Evidence from asymmetric causality. Renewable and Sustainable Energy Reviews, 60, 953-959.

4. Banday, U. J., \& Aneja, R. (2020). Renewable and non-renewable energy consumption, economic growth and carbon emission in BRICS. International Journal of Energy Sector Management, 14(1), 248-260.

5. Belaïd, F., \& Zrelli, M. H. (2019). Renewable and non-renewable electricity consumption, environmental degradation and economic development: Evidence from Mediterranean countries. Energy Policy, 133, 110929.

6. Chen, C., Pinar, M., \& Stengos, T. (2020). Renewable energy consumption and economic growth nexus: Evidence from a threshold model. Energy Policy, 139, 111295.

7. Davidson, N., Mariev, O., \& Turkanova, S. (2021). Does income inequality matter for $\mathrm{CO}_{2}$ emissions in Russian regions? Equilibrium. Quarterly Journal of Economics and Economic Policy, 16(3), 533-551.

8. Destek, M. A., \& Aslan, A. (2017). Renewable and non-renewable energy consumption and economic growth in emerging economies: Evidence from bootstrap panel causality. Renewable Energy, 111, 757-763.

9. European Union (2018, December 11) Directive 2018/2001 of the European Parliament and of the Council of 11 December 2018 on the promotion of the use of energy from renewable sources and amending and subsequently repealing Directives 2001/77/EC and 2003/30/EC. Official Journal of the European Union, 2018, 5, 82-168. https://eurlex.europa.eu/legal-content/EN/TXT/PDF/?uri=CELEX:32018L2001\&from=fr.

10. European Union (2020, January 20). Renewable energy in the EU in 2018. European Commission. https:/ec.europa.eu/eurostat/documents/2995521/10335438/8-23012020AP-EN.pdf/292cf2e5-8870-4525-7ad7-188864ba0c29.

11. Gozgor, G. (2018). A new approach to the renewable energy-growth nexus: evidence from the USA. Environmental Science and Pollution Research, 25(17), 1659016600. https://doi.org/10.1007/s11356-018-1858-9. 
12. Gozgor, G., Lau, C. K. M., \& Lu, Z. (2018). Energy consumption and economic growth: New evidence from the OECD countries. Energy, 153, 27-34.

13. Grossman, G. M., \& Krueger, A. B. (1995). Economic growth and the environment. Quarterly Journal of Economics, 110(2), 353-377.

14. Inglesi-Lotz, R. (2016). The impact of renewable energy consumption to economic growth: A panel data application. Energy Economics, 53, 58-63.

15. Ito, K. (2017). $\mathrm{CO}_{2}$ emissions, renewable and non-renewable energy consumption, and economic growth: Evidence from panel data for developing countries. International Economics, 151, 1-6.

16. Muhammad, A. A., Arshed, N., \& Kousar, N. (2017) Renewable energy consumption and economic growth in member of OIC countries. European Online Journal of Natural and Social Sciences, 6(1), 111-129.

17. Nelson, V.C., \& Starcher, K.L. (2015). Introduction to renewable energy (2nd ed.). CRC Press.

18. Ohler, A., \& Fetters, I. (2014). The causal relationship between renewable electricity generation and GDP growth: A study of energy sources. Energy Economics, 43, 125139.

19. Pesaran, M. H. (1997). The role of economic theory in modelling the long run. The Economic Journal, 107(440), 178-191.

20. Pesaran, M. H., Shin, Y., \& Smith, R. P. (1999). Pooled mean group estimation of dynamic heterogeneous panels. Journal of the American Statistical Association, 94(446), 621-634.

21. Rafindadi, A. A., \& Ozturk, I. (2017). Impacts of renewable energy consumption on the German economic growth: Evidence from combined cointegration test. Renewable and Sustainable Energy Reviews, 75, 1130-1141.

22. Romer, P. (1990) Endogenous technological change. The Journal of Political Economy, 98(5), S71-S102.

23. Soava, G., Mehedintu, A., Sterpu, M., \& Raduteanu, M. (2018). Impact of renewable energy consumption on economic growth: Evidence from European Union countries. Technological and Economic Development of Economy, 24(3), 914-932.

24. United Nations (2015). The 17 Goals: Sustainable development. United Nations, Department of Economic and Social Affairs.

25.Zafar, M. W., Shahbaz, M., Hou, F., \& Sinha, A. (2018). From nonrenewable to renewable energy and its impact on economic growth: the role of research \& development expenditures in Asia-Pacific Economic Cooperation countries. Journal of Cleaner Production, 212, 1166-1178. 